\title{
DETERMINING INITIAL ENRICHMENT, BURNUP, AND COOLING TIME OF PRESSURIZED-WATER-REACTOR SPENT FUEL ASSEMBLIES BY ANALYZING PASSIVE GAMMA SPECTRA MEASURED AT THE CLAB INTERIM-FUEL STORAGE FACILITY IN SWEDEN
}

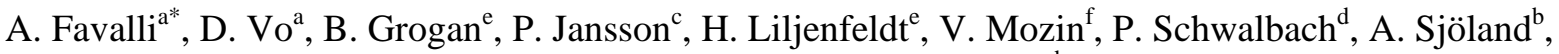 \\ S. J. Tobin ${ }^{\mathrm{a}}$, H. Trellue ${ }^{\mathrm{a}}$, S. Vaccaro ${ }^{\mathrm{d}}$ \\ ${ }^{a}$ Los Alamos National Laboratory, Los Alamos NM, (USA) \\ ${ }^{\mathrm{b}}$ Swedish Nuclear Fuel and Waste Management Company, Stockholm (Sweden), \\ ${ }^{\mathrm{C}}$ Uppsala University, Uppsala (Sweden), \\ ${ }^{\mathrm{d}}$ European Commission, DG Energy, Euratom Safeguards Luxemburg (Luxemburg), \\ ${ }^{\mathrm{e}}$ Oak Ridge National Laboratory, Oak Ridge TN (USA), \\ f Lawrence Livermore National Laboratory, Livermore CA (USA) \\ *email: afavalli@lanl.gov phone +1 5056671429
}

\begin{abstract}
The purpose of the Next Generation Safeguards Initiative (NGSI)-Spent Fuel (SF) project is to strengthen the technical toolkit of safeguards inspectors and/or other interested parties. The NGSISF team is working to achieve the following technical goals more easily and efficiently than in the past using nondestructive assay measurements of spent fuel assemblies: (1) verify the initial enrichment, burnup, and cooling time of facility declaration; (2) detect the diversion or replacement of pins; (3) estimate the plutonium mass [which is also a function of the variables in (1)]; (4) estimate the decay heat; and (5) determine the reactivity of spent fuel assemblies. Since August 2013, a set of measurement campaigns has been conducted at the Central Interim Storage Facility for Spent Nuclear Fuel (Clab), in collaboration with Swedish Nuclear Fuel and Waste Management Company (SKB). One purpose of the measurement campaigns was to acquire passive gamma spectra with high-purity germanium and lanthanum bromide scintillation detectors from Pressurized Water Reactor and Boiling Water Reactor spent fuel assemblies. The absolute ${ }^{137}$ Cs count rate and the ${ }^{154} \mathrm{Eu} /{ }^{137} \mathrm{Cs}$, ${ }^{134} \mathrm{Cs} /{ }^{137} \mathrm{Cs}$, ${ }^{106} \mathrm{Ru} /{ }^{137} \mathrm{Cs}$, and ${ }^{144} \mathrm{Ce} /{ }^{137} \mathrm{Cs}$ isotopic ratios were extracted; these values were used to construct corresponding model functions (which describe each measured quantity's behavior over various combinations of burnup, cooling time, and initial enrichment) and then were used to determine those same quantities in each measured spent fuel assembly. The results obtained in comparison with the operator declared values, as well as the methodology developed, are discussed in detail in the paper.
\end{abstract}

KEYWORDS: passive gamma, initial enrichment, burnup, cooling time nondestructive assay of spent fuel, germanium detector, $\mathrm{LaBr}_{3}$ detector. 


\section{INTRODUCTION}

A team is researching the application of Nondestructive Assay (NDA) to spent fuel assemblies through a project called the Next Generation Safeguards Initiative (NGSI)-Spent Fuel (SF). The team comprises the European Commission, DG Energy, Directorate Euratom Nuclear Safeguards; the Swedish Nuclear Fuel and Waste Management Company; both United Stated and European University ; and United States (US) national laboratories (Los Alamos National Laboratory, Oak Ridge National Laboratory, Lawrence Livermore National Laboratory). As mentioned in the abstract, the research goals of the project include detection of missing/replaced pins, verification of the declaration, estimation of Pu mass, and determination of heat content and reactivity for each assembly. The final objective of this project is to quantify the capability of several integrated nondestructive assay (NDA) instruments to meet the aforementioned goals using combined signatures of neutron, gamma-ray and heat emission.

One driver for the work is the limited availability of verification instruments at the back end of the nuclear fuel cycle. Nuclear safeguards inspectorates, like Euratom safeguards, as well as operators are interested in tools with better quantification capabilities for the future, particularly at a time when the first construction licence for an encapsulation plant and geological repository has been issued in Finland in November 2015. Sweden will follow shortly thereafter. In the frame of this project, a research study was undertaken to determine the initial ${ }^{235} \mathrm{U}$ enrichment, burnup, and cooling time by analyzing the passive gamma spectra of irradiated commercial nuclear light-waterreactor fuel assemblies [1-4]. In the first phase of the NGSI-SF initiative, MCNP-based Monte Carlo libraries of virtual Pressurized Water Reactor (PWR) spent fuel assemblies were developed as a function of various reactor conditions (initial enrichment, burnup, and cooling time) [5]. Simulated passive gamma-ray spectra and neutron count rates from the spent-fuel libraries were analyzed to investigate a methodology to determine initial enrichment, burnup, and cooling time. Methodologies were developed based on the traditional approach in which passive gamma-ray spectroscopy and a passive neutron counting technique are used to develop functional models describing each measured quantity's behavior over various combinations of burnup, cooling time, and initial enrichment and then are used to determine those same quantities in each measured spent fuel assembly [6,7]. An alternative approach that uses a data-mining technique [6,8] has also been investigated; however, this approach is outside the scope of this paper. In the second phase of the project, an experimental activity was undertaken. Since August 2013, a set of measurement 
campaigns has been conducted at the Central Interim Storage Facility for Spent Nuclear Fuel (Clab), in collaboration with Swedish Nuclear Fuel and Waste Management Company (SKB). One purpose of the measurement campaigns was to acquire passive gamma spectra, using high-purity germanium and lanthanum bromide scintillation detectors, from PWR and Boiling Water Reactor (BWR) spent fuel assemblies (to which apply the methods developed in the virtual library space) to determine initial enrichment, burnup, and cooling time [9].

When nuclear fuel in a reactor is irradiated, numerous fission products and minor actinides are produced as a result of particle interactions and subsequent decay. Many of the resulting fission products and actinides are unstable and will decay, emitting gamma rays of various energies. Gamma-ray spectroscopy involves the detection of these photons as a function of energy; isotopes with significant contributions will produce a "peak" of detected gamma-ray counts at the energy associated with the initial isotope.

The passive gamma technique examined for the NGSI-SF project involves a determination of the gamma spectrum coming from spent fuel assemblies and, in particular, the gamma peaks due to five main isotopes: ${ }^{137} \mathrm{Cs}\left(\mathrm{T}_{1 / 2}=30.1 \mathrm{y}\right),{ }^{134} \mathrm{Cs}\left(\mathrm{T}_{1 / 2}=2.06 \mathrm{y}\right),{ }^{154} \mathrm{Eu}\left(\mathrm{T}_{1 / 2}=8.59 \mathrm{y}\right),{ }^{106} \mathrm{Ru}\left(\mathrm{T}_{1 / 2}=1.02 \mathrm{y}\right)$, and ${ }^{144} \mathrm{Ce}\left(\mathrm{T}_{1 / 2}=0.78 \mathrm{y}\right)$. The ${ }^{137} \mathrm{Cs}$ is generally used as a measure of the burnup because an almost linear relationship exists between ${ }^{137} \mathrm{Cs}$ buildup and the burnup. The ${ }^{154} \mathrm{Eu}$ and ${ }^{134} \mathrm{Cs}$ are exploited in the ${ }^{154} \mathrm{Eu} /{ }^{137} \mathrm{Cs}$ and ${ }^{134} \mathrm{Cs} /{ }^{137} \mathrm{Cs}$ isotopic ratios, respectively, and are used to help determine burnup, initial enrichment, and cooling time (BU, IE, and CT, respectively, as used in equations) $[6,7,10,11,12]$. The longer half-life of the ${ }^{154} \mathrm{Eu}$ compared with ${ }^{134} \mathrm{Cs}$ makes the ${ }^{154} \mathrm{Eu} /{ }^{137} \mathrm{Cs}$ ratio, which is perhaps also suitable for longer cooling times (up to $~ 50$ years), also useful. For short cooling times (on the order of $<8$ years), ${ }^{106} \mathrm{Ru}$ and ${ }^{144} \mathrm{Ce}$ also can be used to form the isotopic ratios ${ }^{106} \mathrm{Ru} /{ }^{137} \mathrm{Cs}$ and ${ }^{144} \mathrm{Ce} /{ }^{137} \mathrm{Cs}$, which provide data to improve accuracy in the determination of initial enrichment, burnup, and cooling time. The energy of gamma rays of interest for the analysis ranges from $604.7 \mathrm{keV}$ for one of the main gamma lines of ${ }^{134} \mathrm{Cs}$ up to $2186 \mathrm{keV}$ for ${ }^{144} \mathrm{Ce}$.

\section{BACKGROUND OF MEASUREMENT CAMPAIGNS}

As part of the NGSI-SF project, 25 PWR assemblies (Table 1) were measured with a coaxial highpurity germanium (HPGe) detector system in August 2013 at Clab, Sweden's interim spent nuclear 
fuel storage facility located at Oskarshamn (in the southern part of the country) [9]. The measured PWR spent fuel has initial enrichment in the range of $2.10 \mathrm{wt} \%$ to $4.10 \mathrm{wt} \%$, burnup from 19.61 to $52.63 \mathrm{GWd} / \mathrm{tU}$, and a cooling time from 4.2 to 29.2 years (in August 2013).

\section{\{Here Table 1\}}

The set of fuel assemblies includes five PWR fuel types, with both 15-x-15 and 17-x-17 geometry present. The detector system was based on an HPGe ORTEC GMX with $44 \%$ relative efficiency at $1332 \mathrm{keV}$ of ${ }^{60} \mathrm{Co}$, combined with the Canberra Lynx digital signal analyzer [13] for the acquisition of spectra and list mode data. In February 2014, 17 BWR assemblies also were measured. The detector system was then replaced with the HPGe Canberra GX, featuring 44\% relative efficiency at $1332 \mathrm{keV}$, and combined with a digital MCA-527 by GBS Elektronics [14]. Filters in front of the detectors also were changed. The details of the experimental setups are reported in the overview paper of the passive gamma measurement at Clab [9] prepared by the same collaboration. In October 2014, the same 25 PWR assemblies measured in August 2013 were then re-measured with the new detector system and filter setup. In December 2014, 12 previously measured BWR assemblies and 13 new BWR assemblies were also measured. This document focuses primarily on the first measurement campaign of the PWR assemblies performed in August 2013. The correlation results from the analysis of the August 2013 measurements were then applied to the spectra of the same PWR assemblies measured in October 2014 to calculate the burnup, cooling time, and initial enrichment. The work on the BWR assemblies is described in Reference [9].

\subsection{First Measurement Campaign}

For the measurement campaign performed in August 2013, a total of 41 spectra were obtained of the 25 PWR assemblies (five $15 \times 15$ and twenty $17 \times 17$ ), which are numbered PWR1 through PWR25. All assemblies were measured at a $45^{\circ}$ angle (looking directly at a corner of the square assembly), and gamma spectra were acquired for a 600-s clock time. A 5-mm-slit-width collimator enables a direct line of site to a 15.5-mm-long section of fuel; the entire horizontal width of the fuel was in the field of view. The gamma measurement position was chosen by a scan with a multichannel scaler (MCS), embedded in a Canberra Lynx digital signal analyzer, having a region

of interest in the 662-keV peak of ${ }^{137} \mathrm{Cs}$. The labeling of the measurement position represents the time in seconds for the fuel to move down to the measurement position by means of a step engine. 
The static measurements used in this paper were done at $70 \mathrm{~s}$; in terms of assembly length, this 70-s position corresponds to $150 \mathrm{~cm}$ from the bottom. Figure 1 presents the PWR16 MCS scan, with the 70-s position indicated. Figure 2 presents two examples of gamma spectra acquired for PWR5, with 5.2 years of cooling time, and PWR19, with 28.3 of cooling time.

\{Here Fig.1\}

\{Here Fig.2\}

One assembly (PWR9) was also measured along its length from position 30 s to position 165 s. One assembly (PWR16) was measured from all four corners. PWR20 was measured from three corners. In addition to the normal measurements, the PWR1 and PWR2 assemblies were also measured with extra absorber to attenuate more low-energy gamma rays.

\subsection{Second Measurement Campaign}

For the measurement campaign in October 2014, a total of 200 spectra of the 25 PWR assemblies were obtained. Each assembly was measured at four corners $\left(45^{\circ}, 135^{\circ}, 225^{\circ}\right.$, and $315^{\circ}$ angles $)$ at a static location on the burnup plateau. In contrast to the previous campaigns, the location was determined to be $\sim 120 \mathrm{~cm}$ down from the top of the uranium-containing part of the fuel assembly. Full scans of each corner were also measured as the assembly was moved up and down past the collimator-a motion that took $\sim 400 \mathrm{~s}$. Thus, a total of eight spectra were measured for each assembly.

\section{METHODOLOGY}

Description of the methodology includes extraction of isotope ratios, analysis of the peaks themselves, and an assumption about the relationship of initial enrichment and burnup.

\subsection{Extracting Isotope Ratios}

The spectra were analyzed by the isotopic analysis code Fixed energy Response function Analysis with Multiple efficiencies (FRAM) [15,16], which is designed primarily for plutonium and uranium isotopic analysis. A feature of the code is to determine the ratio of the mass or ratio of the activity of 
one isotope to that of another isotope. Any isotopes can be used; analysis is not necessarily limited to plutonium or uranium nuclides.

The basic working of FRAM is fitting various regions of the spectrum to obtain the areas of the peaks; from these peak areas, the code calculates the efficiencies for photo-peak detection of the peaks. This efficiency includes detector efficiency, geometry, sample self-absorption, and attenuation in materials between the sample and the detector. FRAM then calculates the isotopic mass and activity ratio of the isotopes. Derivation of these ratios is described below.

The photopeak count rate of a gamma ray emitted from an isotope can be expressed as Equation 1 $[6,15-17]$.

$$
C\left(E_{j}^{i}\right)=N^{i} \times B r_{j}^{i} \times \varepsilon\left(E_{j}\right) \times \frac{\ln 2}{T_{1 / 2}^{i}}
$$

where

$C\left(E_{j}^{i}\right)=$ the count rate of the peak $j$ with energy $E_{j}$ emitted from isotope $i$, also called photopeak count rate,

$N^{i} \quad=$ the number of atoms of isotope $i$,

$B r_{j}^{i} \quad=$ the branching ratio of peak $j$ from isotope $i$,

$\varepsilon\left(E_{j}\right)=$ the total efficiency for photo-peak detection of the peak with energy $E_{j}$, and

$T_{1 / 2}^{i}=$ the half-life of isotope $i$.

Combining this equation with the expression for peak $l$ from isotope $k$ gives the expression for the atom ratio of isotope $i$ to isotope $k$ as Equation 2.

$$
\frac{N^{i}}{N^{k}}=\frac{C\left(E_{j}^{i}\right)}{C\left(E_{l}^{k}\right)} \times \frac{T_{1 / 2}^{i}}{T_{1 / 2}^{k}} \times \frac{B r_{l}^{k}}{B r_{j}^{i}} \times \frac{\varepsilon\left(E_{l}\right)}{\varepsilon\left(E_{j}\right)}
$$

The atom ratio on the left of Eq. (2) can be easily converted to the mass or activity ratios that FRAM reports in its output.

From Equation 1, we see that the efficiency $\varepsilon\left(E_{j}\right)$ is proportional to the ratio of the photopeak count rate $C\left(E_{j}^{i}\right)$ and branching ratio $B r_{j}^{i}$.

$$
\varepsilon\left(E_{j}\right) \propto \frac{C\left(E_{j}^{i}\right)}{B r_{j}^{i}} .
$$

The ratio on the right in Equation 3 is defined $[15,16,17]$ as the relative efficiency $R E\left(E_{j}\right)$. The ratio of total efficiency in Equation 2 is equal to the ratio of the relative efficiency, so only the 
shape of the relative efficiency curve as function of energy is needed. Gamma rays emitted from the sample are used to determine the relative efficiency curve. Based on the described method, FRAM code determines the relative efficiency curve from the measured spectrum and reports relative efficiencies, and mass (or activity) ratios in its output.

FRAM is used in this research for the analysis and extraction of the ratios ${ }^{154} \mathrm{Eu} /{ }^{137} \mathrm{Cs},{ }^{134} \mathrm{Cs} /{ }^{137} \mathrm{Cs}$, ${ }^{106} \mathrm{Ru} /{ }^{137} \mathrm{Cs}$, and ${ }^{144} \mathrm{Ce} /{ }^{137} \mathrm{Cs}$. In the paper we refer to these as isotopic ratios, as a shortcut for isotopic mass ratios.

\subsection{Analyzing Peaks}

Of the 25 PWR assemblies, 16 are considered "normal" and 2 are "near normal." In this document, a normal assembly is defined as one that was burned continuously (i.e., burned for $\sim 1$ year, decayed for $\sim 1$ month during reactor refueling, and then burned again) for 4 years or more, i.e. a fuel assembly with a normal reactor operation history. The two near-normal assemblies in this work represent reactor outages of approximately half a year instead of $\sim 1$ month. This document describes first the works done with these 18 normal and near-normal assemblies, and in the second part is described a methodology to identify spent fuel assemblies with anomalous reactor operating history.

Figure 3 shows the distributions of ${ }^{154} \mathrm{Eu} /{ }^{137} \mathrm{Cs}$ and ${ }^{134} \mathrm{Cs} /{ }^{137} \mathrm{Cs}$ and the ${ }^{137} \mathrm{Cs} 662-\mathrm{keV}$ peak count rates as functions of the assembly average burnup for the measurements at position $70 \mathrm{~s}$ of the normal and near-normal assemblies. The data for ${ }^{154} \mathrm{Eu} /{ }^{137} \mathrm{Cs}$ are from all 27 spectra of the 18 assemblies measured different ways, for ${ }^{134} \mathrm{Cs} /{ }^{137} \mathrm{Cs}$ are from 15 spectra with a cooling time less than 20 years, and for ${ }^{137} \mathrm{Cs}$ are 25 out of 27 spectra from identical measurement conditions (i.e., without extra absorbers—see Section 2). The data have been adjusted to the discharge time (i.e., cooling time $=0$ ).

\section{\{Here Fig.3\}}

The inverse problem to determine burnup, initial enrichment, and cooling time is based on the knowledge of model functions, which describe or predict the behavior of a measured quantity for various combinations of burnup, initial enrichment, and cooling time. Model functions are complicated and in the general form not known [7]; we decided to follow a heuristic approach, 
where model functions are expressed as the product of the cooling time contribution in exponential form and the dependence of burnup is a power law or a linear function (see also [18]).

We see that all data appear to be reasonably linear in the burnup range shown in Figure 3, with the ${ }^{137} \mathrm{Cs}$ trend line passing through or nearly through the origin. Thus, we fitted the ${ }^{137} \mathrm{Cs}$ and ${ }^{154} \mathrm{Eu} /{ }^{137} \mathrm{Cs}$ information of 25 spectra (with same measurement conditions) to Equations 4 and 5 (our model functions).

$$
{ }^{137} C s=\left(a B U^{b}\right) e^{-\lambda_{133} C T}
$$

and

$$
\frac{{ }^{154} E u}{{ }^{137} C s}=(c B U+d) e^{-\left(\lambda_{154}-\lambda_{137}\right) C T} .
$$

From the fits, we obtained the coefficients $a=89.4 \pm 14.4, b=0.921 \pm 0.045, c=(1.69 \pm 0.240) \times 10^{-4}$, and $d=0.0121 \pm 0.0011$, where uncertainties are reported as 1-sigma. The coefficient $b$ is close to 1 , as expected for the physics of the production [3].

In a similar manner, we fitted the ${ }^{134} \mathrm{Cs} /{ }^{137} \mathrm{Cs}$ information of the 15 spectra with a cooling time of $<20$ years to Equation 6 .

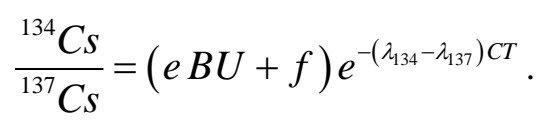

From the fits, we obtained the coefficients $e=0.00263 \pm 0.00029$ and $f=-0.0098 \pm 0.0143$. Similarly, we fitted the ${ }^{106} \mathrm{Ru} /{ }^{137} \mathrm{Cs}$ and ${ }^{144} \mathrm{Ce} /{ }^{137} \mathrm{Cs}$ data of eight passive spectra of assembly with a cooling time of $<8$ years to Equations 7 and 8 .

$$
\frac{{ }^{106} R h}{{ }^{137} C s}=(g B U+h) e^{-\left(\lambda_{106}-\lambda_{137}\right) C T}
$$

and

$$
\frac{{ }^{144} C e}{{ }^{137} \mathrm{Cs}}=(i \mathrm{BU}+j) e^{-\left(\lambda_{144}-\lambda_{137}\right) C T} .
$$


From the fits, the coefficients $g=0.002862( \pm 0.00087), h=-0.044( \pm 0.044), i=0.00718$ $( \pm 0.00094)$, and $j=-0.202( \pm 0.048)$ were obtained.

With these coefficients known, then by means of Eqs. (4-5), (4-6), or (4-8), a burnup and cooling time of a measured assembly can be determined.

\subsection{A Key Assumption}

The reactor operator need to maximize fuel utilization can be seen as the need to maximize the burnup for a given initial enrichment of the fuel. The burnup is roughly related to the initial enrichment through the total energy generated, which consists of reactor power multiplied by the length of time the fuel is burned.

Using the fuel data provided from reactor operator we found a simple correlation for normal assemblies in Equation 9.

$$
I E=l \cdot B U^{k}
$$

with $l=0.31 \pm 0.06$, and $k=0.65 \pm 0.05$.

This relationship looks like "unpublished" guidance that, per each initial enrichment, fixes about the maximum burnup to be reached with the fuel. Equation (9) was used to determine initial enrichment once burnup was extracted from the other correlations. With these coefficients known, Equations 3-7 can be used to determine the burnup and cooling time of a measured assembly.

\section{RESULTS}

For each analysis, there are multiple known equations (two for cooling times $>20$ years, three for cooling times between 8 and 20 years, and five for cooling times $<8$ years), but only two unknown parameters (burnup and cooling time) need to be determined. Thus, we performed a least-squares fit to obtain the burnup and cooling time results. Equation (9) is used to determine the initial enrichment using PWR spectra from the 2013 measurement campaign.

Table 2 shows the deviations of the burnup, cooling time, and initial enrichment of the assemblies (normal reactor history type) when the declared values are compared with the calculated values. The 
averages of the absolute deviations are 4.6\%, 5.6\%, and 5.6\% for the burnup, cooling time, and initial enrichment, respectively.

\section{\{Here Table2\}}

The 15 spectra with cooling times less than 20 years were analyzed with equations 4-6, and Table 3 shows the deviations of the burnup, cooling time, and initial enrichment of the assemblies when the declared and calculated values are compared. The averages of the absolute deviations are 5.2\%, $4.6 \%$, and 3.6\% for the burnup, cooling time, and initial enrichment, respectively. In this table, the second data sets of PWR1 and PWR2 (obtained with extra absorber in front of the detector) were analyzed using only Eqs. (4-6).

\section{\{Here Table 3\}}

Note that Eqs. (4-6) can be used with all the spectra, not just those with a cooling time less than 20

years. For the assemblies in which the cooling time is large, the ${ }^{134} \mathrm{Cs} /{ }^{137} \mathrm{Cs}$ value will have a large uncertainty and therefore will not contribute much to the fit; the results will be similar or the same as if only Eqs. (4) and (5) were used. We then analyzed all 25 spectra from Table 2, including the two spectra with extra absorber for which only Eqs. (4) and (6) were used and ${ }^{137}$ Cs was not. The average of the absolute deviation for all 27 spectra was 4.6\%, 3.5\%, and $4.9 \%$ for the burnup, cooling time, and initial enrichment respectively.

Similarly for the eight assemblies with cooling times less than 8 years, we used Eqs. (7-8) for the analysis, and results are reported in Table 4. The average of the absolute deviations was 4.0\%, 3.9\% and $2.5 \%$ for the burnup, cooling time, and initial enrichment, respectively.

\section{\{Here Table 4\}}

\subsection{Relevant cases for the analysis}

\subsubsection{Measurements along the length of the assembly}

Eight spectra of PWR9 were collected along the length of the assembly from position $30 \mathrm{~s}$ to $165 \mathrm{~s}$. We analyzed the 30- to 120-s spectra using all coefficients $a-j$ with Eqs. (4-8). For the spectra at 150-165 s, we did not use Eq. (4) in the calculations because the measurements were near the edge 
(see Figure 1), causing the measured ${ }^{137} \mathrm{Cs}$ intensity to not be comparable to the other parts of the assembly where the measurement geometry was different. All of these measurements of the PWR9 assembly had one common parameter: the cooling time. Therefore, we fitted the data of all the spectra together while keeping the cooling time the same. The common cooling time result was 6.38 years, and the burnup results appeared to be relatively constant in the middle of the assembly and gradually reduced near the edge. This burnup trend was reasonable: for PWRs, the burnup was smaller at the edge than in the middle because the neutron flux was lower near the edge than in the middle. The initial enrichment was then calculated using Eq. (9), and Table 5 shows the results.

\section{$\{$ Here Table 5\}}

Note that we obtained the coefficients $a-j$ in Eqs. (4-8) using the declared average burnup of the assemblies; from these we calculated the burnup at these individual segments of PWR9.

Note that the calculated initial enrichment values deviated significantly near the edge of the assembly at the 160-s and 165-s marks; this deviation was caused by the reduced burnup common near the ends of the rods. In fact, to determine the initial enrichment along the length of the assembly, a correlation with burnup and measured position would be necessary.

\subsubsection{Measurement at four corners of an assembly}

The PWR16 assembly was measured at four corners at angles of $45^{\circ}, 135^{\circ}, 225^{\circ}$, and $315^{\circ}$. We analyzed the spectra using the ${ }^{137} \mathrm{Cs},{ }^{154} \mathrm{Eu} /{ }^{137} \mathrm{Cs}$, and ${ }^{134} \mathrm{Cs} /{ }^{137} \mathrm{Cs}$ information, together with Eqs. (46). Table 6 shows the results, which agree well with the declared values.

\section{\{Here Tab.6\}}

The PWR20 assembly was also measured at three corners, and one additional overnight measurement was taken at $45^{\circ}$. These spectra were analyzed using the ${ }^{137} \mathrm{Cs}$ and ${ }^{154} \mathrm{Eu} /{ }^{137} \mathrm{Cs}$ information, together with Eqs. (4-5). Table 7 shows the results.

Similar to the results of the PWR16, the results of the PWR20 agreed well with the declared values. In this case, bias was $<2 \%$. We believe that the average results were more accurate than the individual results because the burnups of the four corners of an assembly were slightly different- 
the corners faced different directions, and each fuel rod was irradiated uniquely. Another potential reason for the variations was that the assembly may not have been perfectly straight. When a measurement was done with a horizontal collimator looking at a corner, the segment of the assembly being measured could have been a bit closer or farther than it should be because of the slightly bent assembly. This uncertainty may have added some bias to the 662-keV peak rate of ${ }^{137} \mathrm{Cs}$, increasing the bias of the results. The average of the results minimized this problem and thus gave the most accurate results.

\section{\{Here Tab.7\}}

\subsection{DATA ANALYSIS OF PWR SPECTRA FROM 2014 MEASURMENT CAMPAIGN}

In the later measurement campaign, even though the same 25 PWR assemblies were re-measured, the HPGe detector, multichannel analyzer (MCA), and attenuating sheets changed, whereas the collimation and the object-to-detector distance did not [9]. An additional change from the first campaign is that different ends of the burnup plateau were measured: the first two campaigns measured positions near the bottom of the assembly, whereas the later campaigns measured positions near the top (see Section 2). During the 14 months between measurement campaigns, the some isotopic compositions of the assemblies significantly changed because of decay. A test on these data is an indicator of the performance of the technique.

From the first measurement campaign, we obtained the coefficients $a-j$ used in Eqs. (4-8). The coefficient $a$ is directly proportional to the measured 662-keV peak rate for a particular detector and setup. The later campaign used a different detector and setup, so this coefficient $a$ was adjusted accordingly. By comparing the $662-\mathrm{keV}$ peak rates at $45^{\circ}$ from the first (August 2013) and later campaigns (October 2014), after correction for the ${ }^{137}$ Cs decay during the elapsed time, it was estimated that the efficiency at $662 \mathrm{keV}$ of the later system is $~ 58 \%$ that of the first one because of the change of attenuation sheets in the 2014 campaign [9]. Therefore, the coefficient $a$ was adjusted to 52.2 ( \pm 8.4$)$. With this new coefficient $a$ and the previously obtained coefficients $b-j$, we calculated the burnup (and thus initial enrichment from the burnup) and cooling time of the static PWR spectra. Each assembly was measured at four corners; these four measurements have the same cooling time. Therefore, for each assembly we fit the data of four spectra together while keeping the cooling time the same. 
We analyzed the data of the 16 normal assemblies, 2 near-normal assemblies, and 1 assembly (PWR22) that was burned continuously for 3 years. Table 8 shows the deviations of the burnup, cooling time, and initial enrichment of the assemblies when the declared values were compared with the average values (of four spectra of an assembly) calculated using the coefficients $a-j$ (for assemblies having a cooling time $<10$ years), $a-f$ (for a cooling time $<20$ years), and $a-d$ (for a cooling time $\geq 20$ years). The average of the absolute deviations was $5.4 \%, 3.3 \%$, and $6.8 \%$ for the burnup, cooling time, and initial enrichment, respectively.

\section{\{Here Table 8\}}

Table 5 shows that the analysis worked well for most of the assemblies, except for PWR4, PWR5, and PWR12 and partially for PWR7, where the burnup and cooling time were still obtained with good uncertainty. PWR12 had a long cooling time (26 years); most of the signals of the short-lived

isotopes ${ }^{134} \mathrm{Cs}$, ${ }^{106} \mathrm{Ru}$, and ${ }^{144} \mathrm{Ce}$ was gone, and the uncertainty associated with the average ${ }^{154} \mathrm{Eu} /{ }^{137} \mathrm{Cs}$ ratio was large (7.2\%). Thus, it was not surprising to see that its results deviated significantly from the declared values. The large deviation in the results for PWR4 and PWR5 were not as easily explained because they both had small cooling times, and the data of all the isotopes were used.

To this aim, we used FRAM to analyze the ${ }^{60} \mathrm{Co} /{ }^{137} \mathrm{Cs}$ ratio in the spectra of assemblies PWR1, PWR2, PWR4, and PWR5 of the two campaigns. The PWR1 and PWR2 assemblies were used as control elements for the comparisons because they had similar burnups, cooling times, and initial enrichments as PWR4 and PWR5. Table 9 shows the ${ }^{60} \mathrm{Co} /{ }^{137} \mathrm{Cs}$ ratios of the assemblies.

\section{\{Here Table 9\}}

The ${ }^{60}$ Co was not a fission product but rather the product of neutron activation of the iron in the zirconium alloy claddings of the fuel rods. From the half-lives of ${ }^{60} \mathrm{Co}\left(\mathrm{T}_{1 / 2}=5.3\right.$ years) and ${ }^{137} \mathrm{Cs}$ $\left(T_{1 / 2}=30.1\right.$ years) and the time difference of 14 months between the two measurement campaigns, we expected the ${ }^{60} \mathrm{Co} /{ }^{137} \mathrm{Cs}$ ratios of the later measurements to be $\sim 88 \%$ of that of the first measurements. The results of the PWR1 and PWR2 assemblies agreed within statistics with the expectation. However, for the PWR4 and PWR5 assemblies, the ${ }^{60} \mathrm{Co} /{ }^{137} \mathrm{Cs}$ ratios increased up to 
almost a factor of 2. This increase could have been caused by a spacer, which was in view of the detector in the 2014 measurements and was made of either zirconium alloy or Inconel alloy with a

significant amount of ${ }^{60} \mathrm{Co}$. The spacer affected burnup of the fuel near it when the assembly was irradiated in the reactor, so the burnup near the spacer was slightly different from the burnup at a location far from it. The spacer also absorbed the gamma rays reaching the detector and thus reduced the absolute 662-keV peak rate used in the calculations.

In addition to the two above effects, we discovered another factor that could affect the burnup, cooling time, and initial enrichment calculations. Figure 5 shows the declared burnup profiles of the five assemblies. The length of the assembly was divided into 24 segments, and the measured positions of the first campaign and later campaign were at about segments 10 and 17-18, respectively. The burnup profiles of PWR1 and PWR2 were almost identical and relatively flat from segment 5 to segment 20. The profiles of PWR4 and PWR5 were also identical, but both they and PWR7 were not flat in the middle segments. The ratios of the burnup at segment 10 to the average of segments 17-18 are 1.038, 1.038, and 1.025 for the PWR4, PWR5, and PWR7, respectively. These burnup differences may be one of the components to the deviations shown in Table 8. One technique to cope with the problem of local distortions of burnup due to the presence of grids is to use a camera or vertically scan the fuel to check that measurements are taken far from spacers.

\section{\{Here Fig.5\}}

\subsection{METHODOLOGY TO IDENTIFY SPENT FUEL ASSEMBLIES WITH ANOMALOUS REACTOR OPERATING HISTORY}

Based on the analysis approach described in the previous section, in this section a methodology is introduced that could potentially identify an assembly with anomalous reactor operating history. For the following analysis, an assembly that burned continuously to the end of its useful life (about 4 years or more) was defined as normal (and as having a normal reactor operating history), whereas any assembly that did not satisfy this condition was considered to have had an anomalous reactor operating history. In the context of passive gamma, we outlined a method to identify, with some confidence, assemblies with anomalous reactor operating histories. 
In the previous sections, we saw that for a fuel assembly with a cooling time of $<\sim 20$ years, the burnup and cooling time (two unknowns) were obtained by fitting the three equations with three input pieces of information: ${ }^{137} \mathrm{Cs},{ }^{154} \mathrm{Eu} /{ }^{137} \mathrm{Cs}$, and ${ }^{134} \mathrm{Cs} /{ }^{137} \mathrm{Cs}$. Note that ${ }^{137} \mathrm{Cs}$ and ${ }^{154} \mathrm{Eu} /{ }^{137} \mathrm{Cs}$, with their long half-lives, were most insensitive to the dwell time of the fuel in the reactor, whereas the short life of ${ }^{134} \mathrm{Cs} /{ }^{137} \mathrm{Cs}$ made this ratio sensitive to dwell time. Then the large deviation of the ${ }^{134} \mathrm{Cs} /{ }^{137} \mathrm{Cs}$ ratio obtained from the measurement data, compared with the calculated ratio, indicated (because of the different half-life) an assembly with anomalous irradiation history in the reactor. To quantify the deviation, we introduced a metric called the number of sigma for the ${ }^{134} \mathrm{Cs} /{ }^{137} \mathrm{Cs}$ ratio as \#sigma =(measured data-calculated)/sigma, where sigma was the 1-sigma uncertainty associated with the ${ }^{134} \mathrm{Cs} /{ }^{137} \mathrm{Cs}$ experimentally-determined ratio. With an appropriate threshold, in terms of number of sigma, assemblies with anomalous operating history were identified. A tradeoff between the sensitivity of the threshold and the false identification of the normal assemblies was necessary: a high threshold may lead to some slightly anomalous assemblies being missed, whereas a low threshold may lead to some normal assemblies being misidentified as not normal. For our data, a threshold was set at 8 in the number of sigma. In general, a positive \#sigma indicated that the assembly was not completely burned, whereas a negative value indicated that the assembly was not burned continuously, with a stopgap(s) between burned periods. For an assembly that was not burned continuously and completely, the \#sigma was either positive or negative. Here it is worth saying that Equation 9, which assumed fuel used at the maximum of capacity, is not in general true in such scenarios. The results of the introduced methodology, based on the data of the 2013 campaign, are reported in Table 10.

\section{\{Here Table 10\}}

Table 10 shows how the methodology with a threshold at 8 was able to identify seven cases of anomalous reactor operating history. The analysis missed PWR14 and three other measurements of PWR16 because these measurements only deviated slightly from the norm (i.e., a half-year stop gap). The analysis also missed PWR6 that had a 2-year stopgap after the second cycle. Curiously, the burnup, cooling time, and initial enrichment results of PWR6 agreed well with the declared values. The analysis misidentified the normal PWR7 as abnormal with a \#sigma of -11. Probably because its initial enrichment and burnup appeared to be different from those with similar initial 
enrichments and burnups. For example, with similar loading to a discharge time of $~ 3.8$ years, the initial enrichment of 3.94\% of PWR7 was the same as that of PWR5, but its burnup was 5\% lower. When comparing the results with PWR8, which had a similar burnup, the initial enrichment of PWR7 was 20\% larger than that of PWR8. These observed differences with other normal assemblies indicated that the PWR7 assembly was probably burned in a somewhat variant way than other assemblies, such as its position inside the reactor during 4 years of irradiation.

The effectiveness of the methodology was improved when applying it to spent fuel assemblies with a short cooling time (i.e. $<\sim 5$ years) by including ${ }^{144} \mathrm{Ce} /{ }^{137} \mathrm{Cs}$ and ${ }^{106} \mathrm{Ru} /{ }^{137} \mathrm{Cs}$ ratios in the analysis.

\section{LaBr $_{3}$ SCINTILLATION DETECTOR AS AN ALTERNATIVE DETECTOR SYSTEM}

Semiconductor HPGe detectors are state of the art for gamma spectroscopy of spent fuel ( $\sim 2 \%$ at the 662-keV gamma ray of ${ }^{137} \mathrm{Cs}$ ). In the context of HPGe, an important limitation is the inability of a single crystal to tolerate high count rates. Note that fully spent fuel assemblies produce $10^{15}$ gamma rays per second, resulting in the count-rate capability being an important criterion among the requirements. New scintillation detectors, such as lanthanum bromide $\left(\mathrm{LaBr}_{3}\right)$, offer both significantly higher count-rate capabilities and higher energy resolution ( $3 \%$ at the $662-\mathrm{keV}$ gamma ray of ${ }^{137} \mathrm{Cs}$ ) than the traditional sodium iodide (NaI) scintillator ( $\sim \%$ at the $662-\mathrm{keV}$ gamma ray of ${ }^{137} \mathrm{Cs}$ ) [19-21]. These new scintillation detectors may be an effective alternative for nuclear spent fuel applications, provided that the reduced resolution is sufficient for the measurement task at hand-in the current case, the measurement of passive gamma rays. An additional advantage of a scintillation-based detector such as the $\mathrm{LaBr}_{3}$ detector is that it does not need a cooling system. Thus, an experimental comparison was performed during the measurement campaign at Clab.

A 2-in.-long-x-2-in.-diameter $\mathrm{LaBr}_{3}$ scintillation detector with a negatively biased photomultiplier tube (PMT) (PM R6231-100 Hamamatsu with a 8.5-ns rise time), combined with a tapered active high-voltage divider [11], was used in the setup. As for the HPGe, Canberra's Lynx front-end MCA was used for the data acquisition. The passive gamma spectrum of PWR5 (initial enrichment = 
3.94\%, burnup $=46.9 \mathrm{GWd} / \mathrm{tU}$, and cooling time $=5.2$ years) was acquired and is reported in Fig.5. The count rate as reported by the MCA was 54,187, and the dead time was $3 \%$.

\section{\{Here Fig.5\}}

The spectrum was analyzed using FRAM, following the same approach described in Section 3.

From the analysis, we obtained ${ }^{134} \mathrm{Cs} /{ }^{137} \mathrm{Cs}=2.22 \times 10^{-2}( \pm 1.57 \%)$ and ${ }^{154} \mathrm{Eu} /{ }^{137} \mathrm{Cs}=1.54 \times 10^{-2}$ ( $\pm 4.22 \%$ ), to be compared with the ratios obtained using an HPGe detector having ${ }^{134} \mathrm{Cs} /{ }^{137} \mathrm{Cs}=$ $2.12 \times 10^{-2}( \pm 0.31 \%)$ and ${ }^{154} \mathrm{Eu} /{ }^{137} \mathrm{Cs}=1.49 \times 10^{-2}( \pm 0.51 \%)$. The results in terms of accuracy were reasonable, although the reduced energy resolution affected the precision. However, the ability of the $\mathrm{LaBr}_{3}$ detector to work at a very high count rate [on the order of mega counts per second (Mcps), to be compared with 150 kcps of HPGe] [21] and the fact that it does not need a cooling system make it an attractive alternative for nuclear spent fuel gamma measurements in a highcount-rate gamma field, despite its lower energy resolution compared with HPGe.

\section{CONCLUSIONS}

Passive gamma-ray spectra from irradiated fuel stored at the Clab interim storage facility in Sweden were analyzed to determine three parameters defining the reactor condition of a spent fuel assembly: burnup, cooling time, and initial enrichment. The absolute ${ }^{137} \mathrm{Cs}$ count rate and the ${ }^{154} \mathrm{Eu} /{ }^{137} \mathrm{Cs},{ }^{134} \mathrm{Cs} /{ }^{137} \mathrm{Cs},{ }^{106} \mathrm{Ru} /{ }^{137} \mathrm{Cs}$, and ${ }^{144} \mathrm{Ce} /{ }^{137} \mathrm{Cs}$ ratios have been used to construct model functions, which describe each measured quantity's behavior over various combinations of burnup, cooling time, and initial enrichment. Results led to subsequent determination of burnup, cooling time, and initial enrichment of each measured PWR spent fuel assembly using the average fitting parameters calculated.

The study resulted in a simple-to-use technique to estimate the burnup, cooling time, and initial enrichment of the spent fuel assemblies. These burnup, cooling time, and initial enrichment results were obtained despite the simplicity of the measurement technique and rapid real-time measurement of only 10 minutes. The technique was tested with the data from two different measurement campaigns (2013 and 2014) with only slight variations in resulting equation fitting. Of the burnup and cooling time results of 2014 campaign, 70\% deviated $<3 \%$ from the declared values (Table 8). For the few that deviated significantly from the declared values, we found possible reasons for the 
large biases. Based on the technique we developed, we outlined a methodology to identify, with some confidence, spent fuel assemblies with anomalous burning operating history in the reactor.

Finally, the viability of using a $\mathrm{LaBr}_{3}$ scintillation detector as an alternative detector to HPGe was discussed. A comparison of spectra collected with $\mathrm{LaBr}_{3}$ and HPGe of spent nuclear fuel was reported, and the results were discussed.

\section{ACKNOWLEDGMENT}

The authors acknowledge the support of the Next Generation Safeguards Initiative (NGSI), Office of Nonproliferation and Arms Control (NPAC), National Nuclear Security Administration (NNSA), and SKB's Central Interim Storage Facility for Spent Nuclear Fuel (Clab), Sweden. Suggestions made by anonymous reviewers have helped to refine this article, and we acknowledge them here. 


\section{REFERENCES}

[1] S.J. Tobin, H. Liljenfeldt, H.R. Trellue, et al., "Experimental and Analytical Plans for the Non-Destructive Assay System of the Swedish Encapsulation and Repository Facilities," in "Proceedings of International Atomic Energy Agency Symposium on International Safeguards: Linking Strategy, Implementation and People,” Vienna, Austria (October 2014).

[2] K.D. Veal, S.A. LaMontagne, S.J. Tobin, and L.E. Smith, "NGSI Program to Investigate Techniques for the Direct Measurement of Plutonium in Spent LWR Fuels by Non-Destructive Assay,” Annual Mtg. of the Institute of Nuclear Material Management, Baltimore, MD (2010).

[3] M.A. Humphrey, S.T. Tobin, and K.D.Veal, “The Next Generation Safeguards Initiative's Spent Fuel Nondestructive Assay Project,” Journal of Nuclear Material Management 40, 3:XL (2012).

[4] S.J. Tobin, H.O. Menlove, M.T. Swinhoe, P. Blanc, T. Burr, L.G. Evans, A. Favalli, M.L. Fensin, C.R. Freeman, J. Galloway, J. Gerhart, A. Rajasingam, E. Rauch, N.P. Sandoval, H. Trellue, T.J. Ulrich, J.L. Conlin, S. Croft, J. Hendricks, V. Henzl, D. Henzlova, J.M. Eigenbrodt, W.E. Koehler, D.W. Lee, T.H. Lee, A.M. LeFleur, M.A. Schear, M.A. Humphrey, L. Smith, K.K. Anderson, L.W. Campbell, A. Casella, C. Gesh, M.W. Shaver, A. Misner, S.D. Amber, B.A. Ludewigt, B. Quiter, A. Solodov, W. Charlton, A. Stafford, A.M. LaFleur, C. Romano, J. Cheatham, M. Ehinger, S.J. Thompson, D.L. Chichester, J.L. Sterbent, J. Hu, A. Hunt, W.E. Koehler, V. Mozin, J.G. Richard, and L.E. Smith, "Technical Cross-Cutting Issues for the Next Generation Safeguards Initiative's Spent Fuel Nondestructive Assay Project,” Journal of Nuclear Materials Management 40(3), pp.18-24, 2012.

[5] J.D. Galloway, H.R. Trellue, M.L. Fensin, and B.L. Broadhead, "Design and Description of the NGSI Spent Fuel Library with an Emphasis on Passive Gamma Signal,” Journal of Nuclear Materials Management 40:3, 25-35 (2012).

[6] A. Favalli et al., "Determination of Initial Enrichment, Burnp, Cooling Time of PWR Spent Fuel Assemblies by Analysis of Passive Gamma Spectra and Neutron Count Rate,” Los Alamos National Laboratory report LA-UR-1327537 (2013).

[7] A. Favalli, J. Gerhart, J. Hu, D.W. Lee, M.T. Swinhoe, S.J. Tobin, and H.R. Trellue, "On Determination of Initial Enrichment, Burnup, Cooling Time of PWR Spent Fuel Assemblies by Analysis of Passive Gamma Spectra and Neutron Count Rate,” 53 ${ }^{\text {rd }}$ INMM Annual Meeting 2012, Orlando, USA.

[8] T. Burr, H. Trellue, J. Dowel, S. Tobin, A. Favalli, V. Henzl, and V. Mozin, Integrated Nondestructive Assay Systems to Estimate Plutonium in Spent Fuel Assemblies, Nuclear Science and Engineering, 179, 2015, pages 1-12.

[9] S. Vaccaro, S.J. Tobin, A. Favalli, B. Grogan, P. Jansson, H. Liljenfeldt, V. Mozin, J. Hu, P. Schwalbach, A. Sjöland, H. Trellue, and D. Vo, "Overview of Passive Gamma Measurements of Spent Fuel Assemblies with High Purity Germanium Detectors at the Central Interim Storage Facility for Spent Nuclear Fuel in Sweden,” Los Alamos National Laboratory report LA-UR-15-23993 (2015)( report available thourgh Los Alamos National Laboratory Library or through the first author at the email address: Stefano.VACCARO@ec.europa.eu), to be submtted in NIM-A.

[10] A.S. Chesterman, A. Simpson, and M. Clapham, "Burnup Credit Measurements for Cask Loading Compliance-A Review of Techniques and Calibration Philosophies," WM2011 Conference, Phoenix, (2011). Available at http://www.wmsym.org/archives/2011/papers/11194.pdf (last accessed on October 21, 2015).

[11] C. William et al., "Nondestructive Assay of Spent Nuclear Fuel with Gamma-Ray Spectroscopy,” Annals of Nuclear Energy 33 (2006).

[12] P.M. Rinard, “Gamma Doses from Irradiated Assemblies under Water,” Los Alamos National Laboratory report LA-7914-MS (1979).

[13] Canberra Lynx ${ }^{\circledR}$ Digital Signal Analyzer datasheet, http://www.canberra.com/products/radiochemistry_lab/pdf/ Lynx-SS-C38658.pdf, last accessed on November 3, 2015. 
[14] GBS Elektronik GmbH: MCA-527 Multi Channel Analyser, User Manual. http://www.gbs-elektronik.de/fileadmin/ download/manuals/MCA527_Manual_2012_08_07.pdf, (last accessed November 3, 2015).

[15] T.E. Sampson, T.A. Kelley, and D.T. Vo, "Application Guide to Gamma-Ray Isotopic Analysis Using the FRAM Software,” Los Alamos National Laboratory report LA-14018 (2003).

[16] D.T. Vo and T.E. Sampson, FRAM, Version 5 User Manual, Los Alamos National Laboratory document LA-UR11-03005 (2011).

[17] D. Reilly, N. Ensslin, H. Smith Jr., and S. Kreiner, "Passive Nondestructive Assay of Nuclear Materials,” Los Alamos National Laboratory report LA-UR-90-732 (1990), URL (2015-05-07): http://www.lanl.gov/ orgs/n/n1/panda/, last accessed November 3, 2015.

[18] J.R. Phillips, J.KHalbig, D.M.Lee, S.E.Beach, T.R.Bement, E.Dermendjiev, C.R.Hatcher, K.Kaieda, E.G.Medina, "Application of Nondestructive Gamma-Ray and Neutron Techniques for the Safeguarding of Irradiation Fuel Materials," Los Alamos National Laboratory report LA-8212 (1980), URL (2016-02-16): http://www.osti.gov/scitech/servlets/purl/5277679-FVEIuh/

[19] A. Favalli, H.C. Mehner, V. Ciriello, and B. Pedersen, "Investigation of the PGNAA Using the $\mathrm{LaBr}_{3}$ Scintillator Detector,” Applied Radiation Isotopes 68:4-5, 901-904 (2010).

[20] A. Favalli, H-C. Mehner, and F.Simonelli, "Wide Energy Range Efficiency Calibration for a Lanthanum Bromide Scintillation Detector,” Radiation Measurement 43, issues 2-6, 2008, pp. 506-509.

[21] A. Favalli, M. Iliev, K. Ianakiev, J.L. Thron, E.T.E. Reedy, A.W. Hunt, V. Mozin, and B. Ludewigt, "Delayed Gamma-Ray Spectroscopy with Lanthanum Bromide Detector for Non-Destructive Assay of Nuclear Material," $55^{\text {th }}$ INMM Annual Meeting, Atlanta, July 2014. 


\section{Figure Captions}

Figure 1. The ${ }^{137}$ Cs-time- profile of PWR16, moving down (August 2013 campaign). The bin width is 1 s.

Figure 2. PWR 5 (Fig. a) and PWR 19 (Fig. b) acquired gamma spectra at the 2013 campaign. PWR5 and PWR19 have a cooling time of 5.2 years and 28.3 years, respectively. PWR5 was acquired for a clock time of $603 \mathrm{~s}$, with a dead time of 43.02\%, whereas PWR19 was acquired with a clock time of $2314 \mathrm{~s}$, with a dead time of $9.44 \%$.

Figure 3. Distributions of ${ }^{154} \mathrm{Eu} /{ }^{137} \mathrm{Cs}$ and ${ }^{134} \mathrm{Cs} /{ }^{137} \mathrm{Cs}$ and the $662-\mathrm{keV}$ peak rate of ${ }^{137} \mathrm{Cs}$ as functions of the burnup. The ${ }^{154} \mathrm{Eu} /{ }^{137} \mathrm{Cs}$ data were multiplied by a factor of 4 for clarity in the display. The vertical scale for the ratios is on the left, and the vertical scale for the $662-\mathrm{keV}$ peak of ${ }^{137} \mathrm{Cs}$ is on the right. The lines are the linear fit to data.

Figure 4. Declared burnup profiles of assemblies PWR1, PWR2, PWR4, PWR5, and PWR7.

Figure 5. Passive gamma-ray spectrum of PWR5 acquired using the $\mathrm{LaBr}_{3}$ detector.

\section{Table Captions}

Table 1. Fuel characteristics for the PWR assemblies measured at Clab. The fuel type was indicated as a general PWR Fuel Type $x$, with $x$ ranging between 1 and 5 .

Table 2. Deviations (measured/declared -1) of the predicted BU, CT, and IE of the assemblies compared to the actual (note that not all assemblies were measured an equal number of times).

Table 3. Deviations (measured/declared -1) of the BU, CT, and IE of predicted compared to actual values of the 15 spectra with CT of $<20$ years

Table 4. Deviations (measured/declared -1) of the BU, CT, and IE of the spectra of predicted compared to actual values with CT of $<8$ years

Table 5. Predicted BU, CT, and IE results of PWR9 along the length of the assembly when analyzed using the same cooling time for all measurements. From the 150-s mark to the 165-s mark, measurements were acquired near the edge of the fuel.

Table 6. Predicted BU, CT, and IE results of PWR16 from four corners and the average results.

Table 7. Predicted BU, CT, and IE results of PWR20 from three corners and the average results.

Table 8. Deviations (measured/declared -1) of the BU, CT, and IE of predicted compared to actual values of the assemblies (note that not all assemblies were measured an equal number of times).

Table 9. The average (Ave). measured ${ }^{60} \mathrm{Co} /{ }^{137} \mathrm{Cs}$ ratios of the assemblies.

Table 10. Results of the methodology for the identification of the assembly with anomalous reactor history in the reactor (see text for the meaning of \#sigma). 
Figure 1. The ${ }^{137}$ Cs-time- profile of PWR16, moving down (August 2013 campaign). The bin width is $1 \mathrm{~s}$. The vertical line indicates the position $70 \mathrm{~s}(\sim 150 \mathrm{~cm}$ from the bottom of the fuel) where the static spectra were measured.

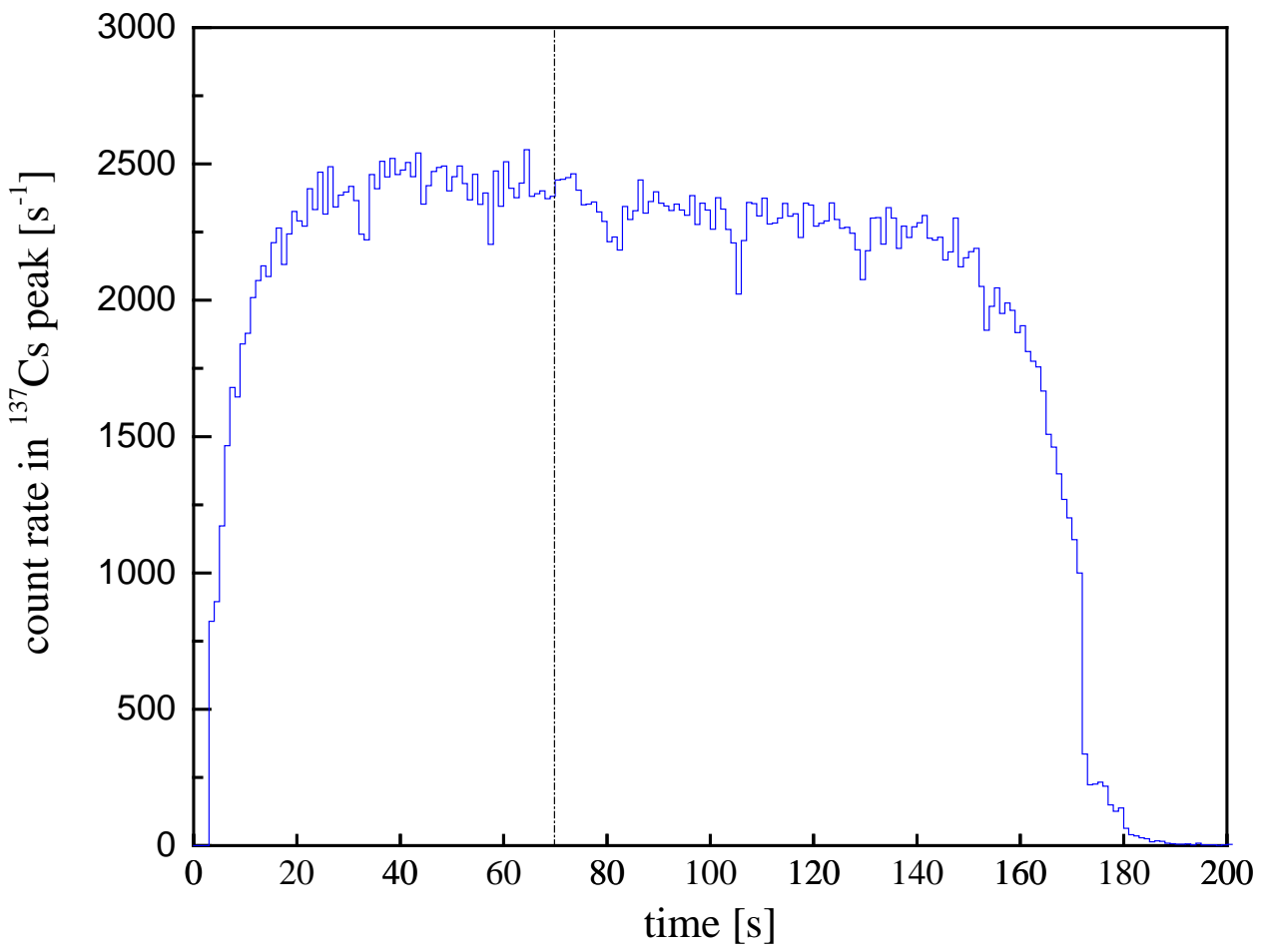


Figure 2. PWR 5 (Fig. a) and PWR 19 (Fig. b) acquired gamma spectra at the 2013 campaign using HPGe and Canberra Lynx MCA. PWR5 and PWR19 have a cooling time of 5.2 years and 28.3 years, respectively. PWR5 was acquired for a clock time of $603 \mathrm{~s}$, with a dead time of 43.02\%, whereas PWR19 was acquired with a clock time of $2314 \mathrm{~s}$, with a dead time of $9.44 \%$.

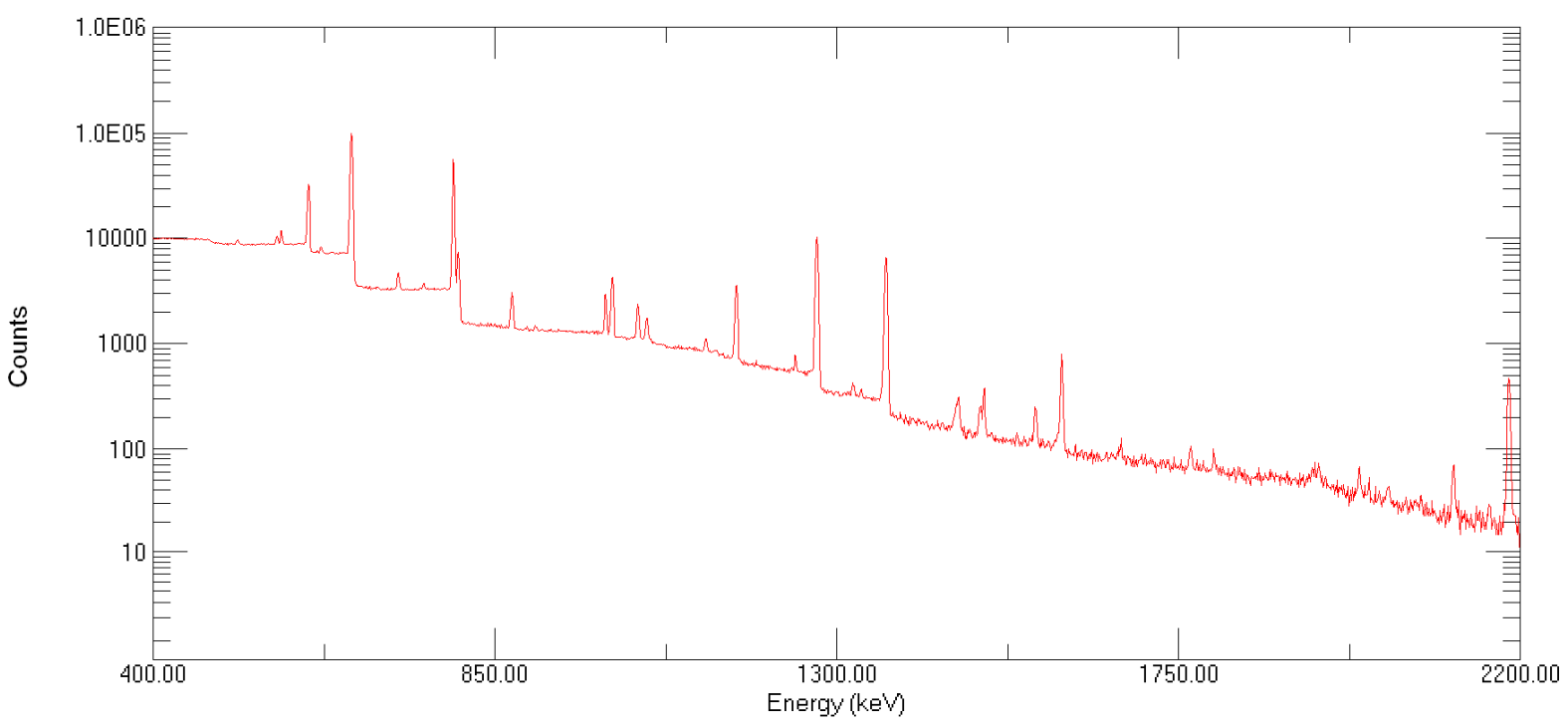

(a)

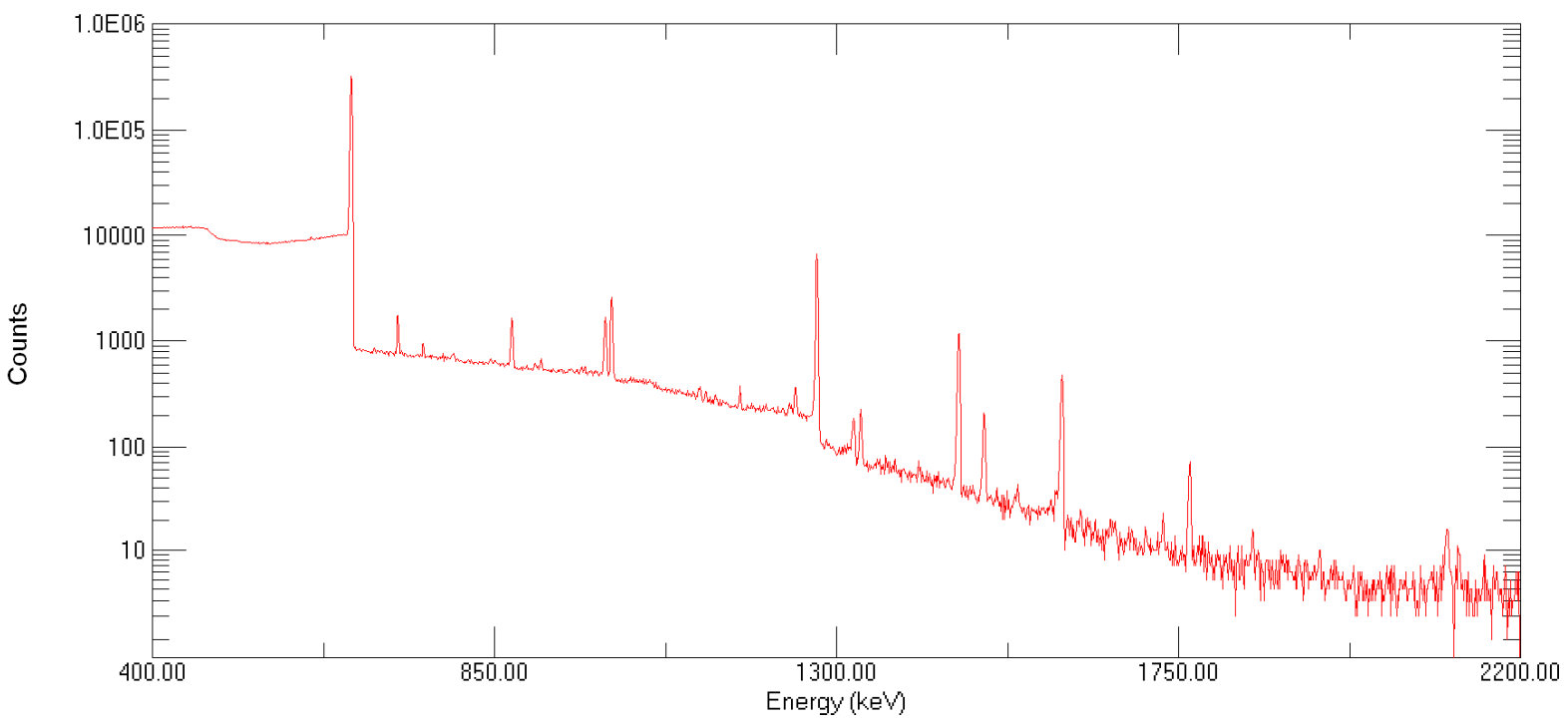

(b) 
Figure 3. (color online version) Distributions of ${ }^{154} \mathrm{Eu} /{ }^{137} \mathrm{Cs}$ and ${ }^{134} \mathrm{Cs} /{ }^{137} \mathrm{Cs}$ and the $662-\mathrm{keV}$ peak rate of ${ }^{137} \mathrm{Cs}$ as functions of the burnup. The ${ }^{154} \mathrm{Eu} /{ }^{137} \mathrm{Cs}$ data were multiplied by a factor of 4 for clarity in the display. The vertical scale for the ratios is on the left, and the vertical scale for the $662-k e V$ peak of ${ }^{137} \mathrm{Cs}$ is on the right. The lines are the linear fit to data.

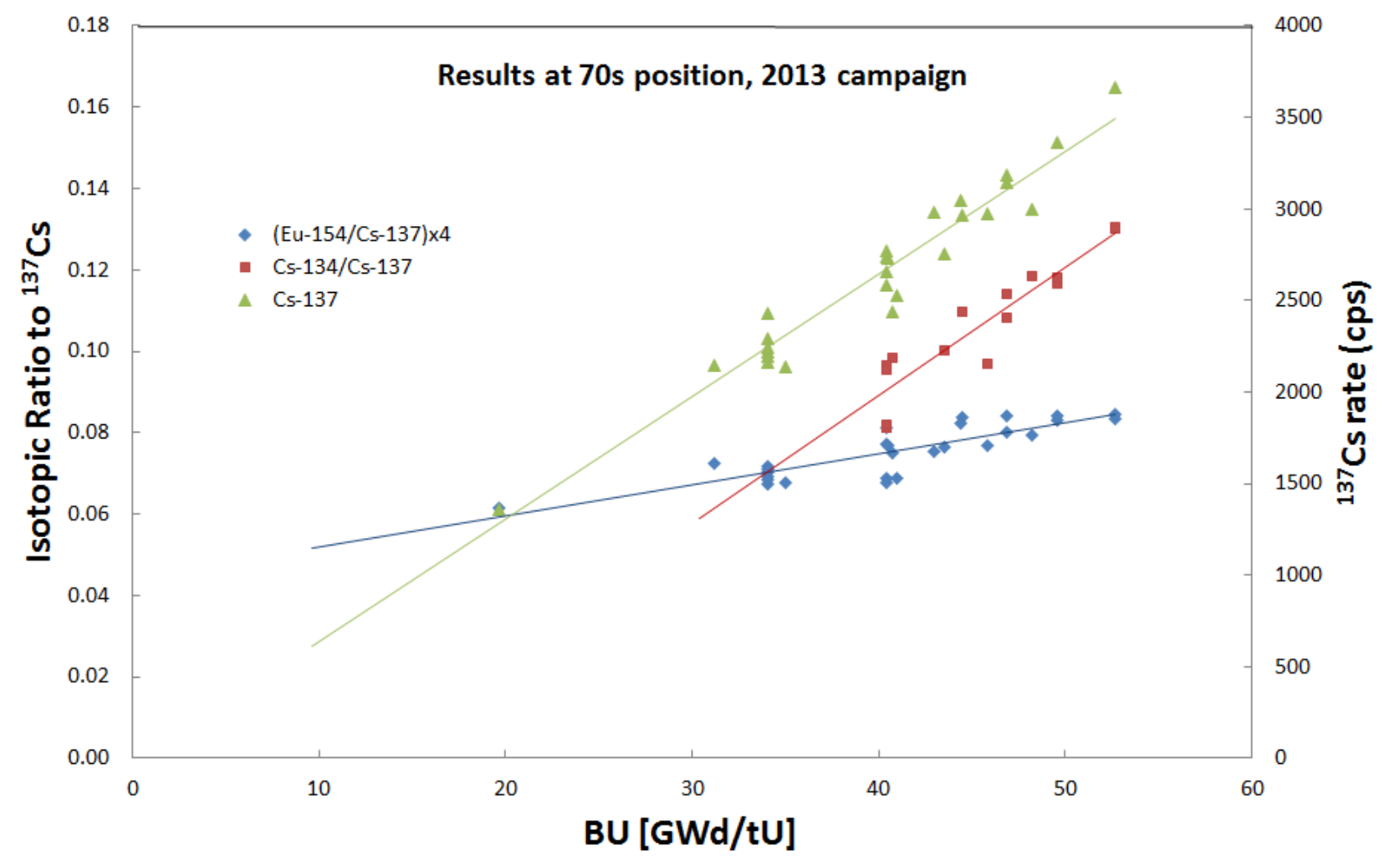


Figure 4. (Color online version) Declared burnup profiles of assemblies PWR1, PWR2, PWR4, PWR5, and PWR7.The pair PWR1 \& PWR2 and PWR4 \& PWR5 show the same profile in the resolution of the plot.

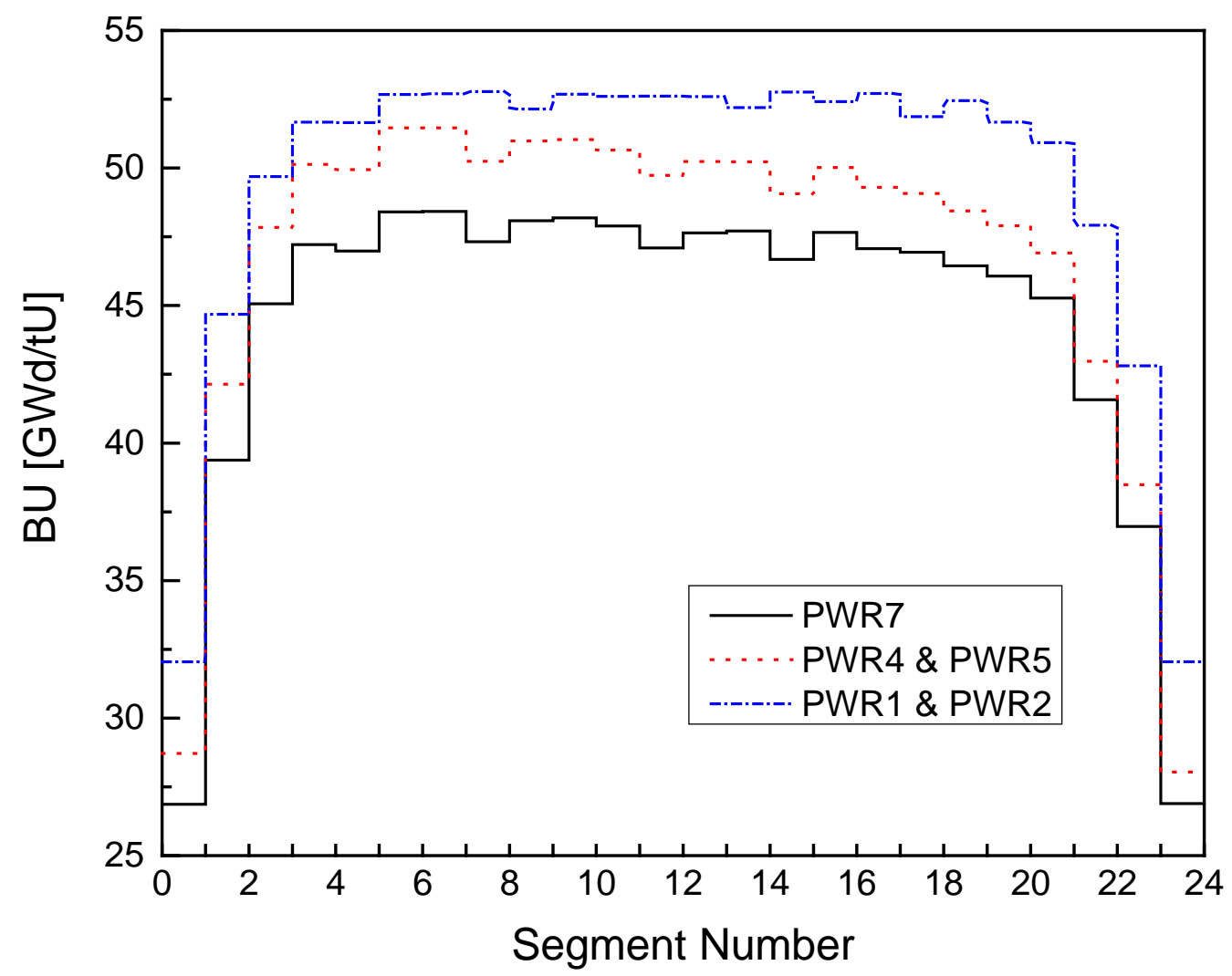


Figure 5. Passive gamma-ray spectrum of $P W R 5$ acquired using the $\mathrm{LaBr}_{3}$ detector.

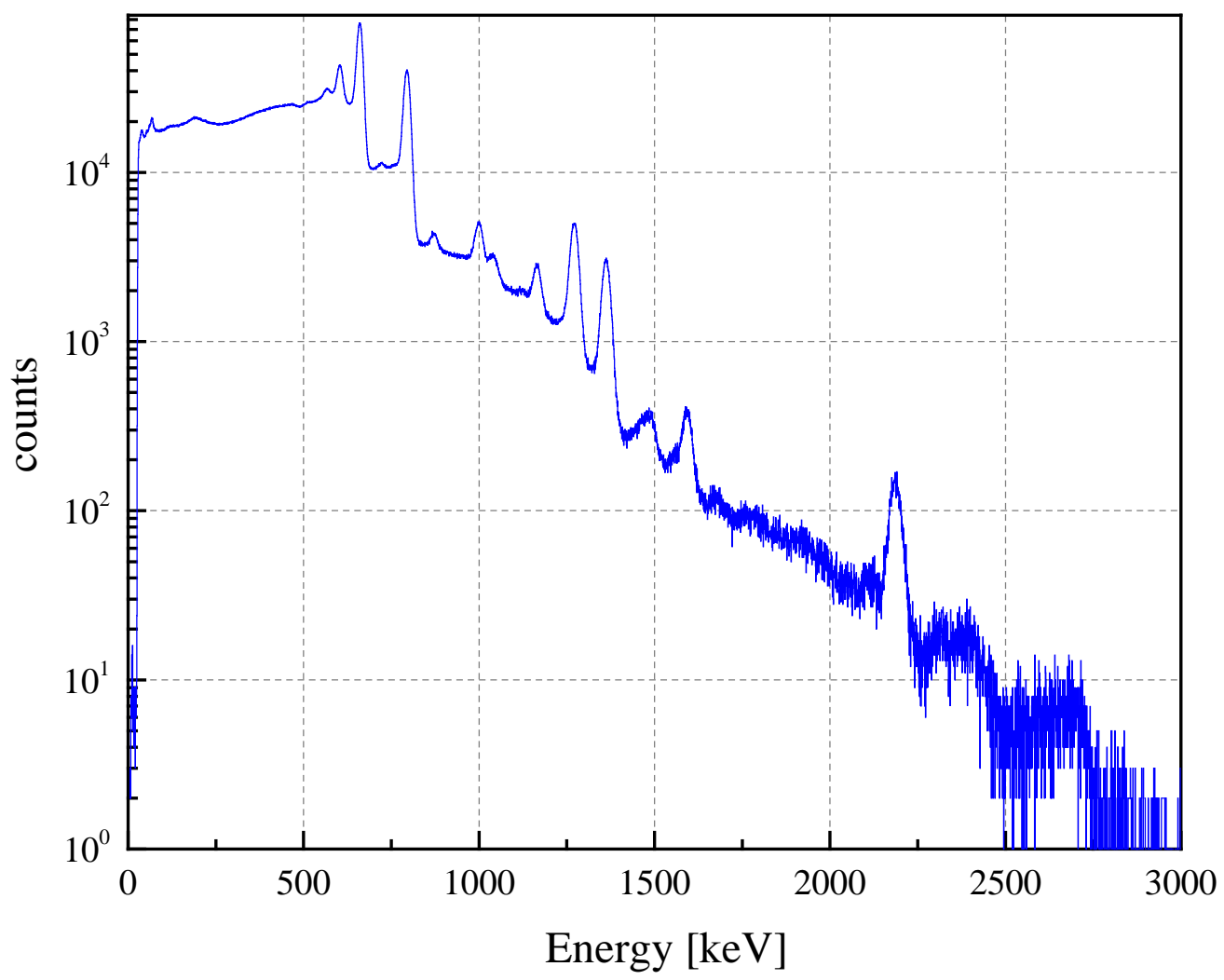


Table 1. Fuel characteristics for the PWR assemblies measured at Clab. The fuel type was indicated as a general $P W R$ Fuel Type $x$, with $x$ ranging between 1 and 5 .

\begin{tabular}{|c|c|c|c|c|}
\hline $\begin{array}{c}\text { Assembly } \\
\text { ID }\end{array}$ & $\begin{array}{l}\text { Fuel } \\
\text { Type }\end{array}$ & $\begin{array}{c}\text { Initial }{ }^{235} \mathrm{U} \\
\text { Enrichment } \\
(\%)\end{array}$ & $\begin{array}{c}\text { Burnup } \\
\text { [GWd/tU] }\end{array}$ & $\begin{array}{c}\text { Cooling } \\
\text { Time } \\
\text { [years] } \\
\text { (Reference August 2013) }\end{array}$ \\
\hline PWR1 & 15x15 PWR Fuel Type 1 & 4.10 & 52.6 & 4.2 \\
\hline PWR2 & 15x15 PWR Fuel Type 1 & 3.93 & 49.6 & 4.2 \\
\hline PWR3 & 17x17 PWR Fuel Type 1 & 3.69 & 48.2 & 13.1 \\
\hline PWR4 & 17x17 PWR Fuel Type 2 & 3.93 & 46.9 & 5.2 \\
\hline PWR5 & 17x17 PWR Fuel Type 2 & 3.94 & 46.9 & 5.2 \\
\hline PWR6 & 17x17 PWR Fuel Type 3 & 3.60 & 45.7 & 14.1 \\
\hline PWR7 & 17x17 PWR Fuel Type 4 & 3.94 & 44.5 & 6.1 \\
\hline PWR8 & 17x17 PWR Fuel Type 5 & 3.30 & 44.4 & 24.9 \\
\hline PWR9 & 15x15 PWR Fuel Type 2 & 3.71 & 45.8 & 6.0 \\
\hline PWR10 & 17x17 PWR Fuel Type 1 & 3.70 & 43.5 & 15.2 \\
\hline PWR11 & 17x17 PWR Fuel Type 1 & 3.51 & 43.2 & 13.2 \\
\hline PWR12 & 17x17 PWR Fuel Type 5 & 3.30 & 43.0 & 24.9 \\
\hline PWR13 & 15x15 PWR Fuel Type 3 & 3.20 & 40.9 & 26.3 \\
\hline PWR14 & 17x17 PWR Fuel Type 2 & 3.51 & 40.7 & 16.2 \\
\hline PWR15 & 17x17 PWR Fuel Type 5 & 2.80 & 40.5 & 26.0 \\
\hline PWR16 & 17x17 PWR Fuel Type 1 & 3.60 & 40.4 & 17.2 \\
\hline PWR17 & 17x17 PWR Fuel Type 1 & 3.70 & 40.3 & 14.0 \\
\hline PWR18 & 17x17 PWR Fuel Type 1 & 3.52 & 39.8 & 18.2 \\
\hline PWR19 & 15x15 PWR Fuel Type 4 & 3.20 & 35.0 & 28.3 \\
\hline PWR20 & 17x17 PWR Fuel Type 5 & 3.10 & 34.0 & 27.2 \\
\hline PWR21 & 17x17 PWR Fuel Type 5 & 3.10 & 34.0 & 27.2 \\
\hline PWR22 & 17x17 PWR Fuel Type 5 & 2.80 & 31.2 & 27.0 \\
\hline PWR23 & 17x17 PWR Fuel Type 1 & 3.60 & 28.5 & 17.2 \\
\hline PWR24 & 17x17 PWR Fuel Type 5 & 2.10 & 23.2 & 18.2 \\
\hline PWR25 & 17x17 PWR Fuel Type 5 & 2.10 & 19.6 & 29.3 \\
\hline
\end{tabular}


Table 2. Deviations (measured/declared -1) of the predicted BU, CT, and IE of the assemblies compared to the actual (note that not all assemblies were measured an equal number of times).

\begin{tabular}{|l|c|c|c|l|c|c|c|}
\hline Assembly & $\begin{array}{c}\text { BU } \\
\text { [GWd/tU] }\end{array}$ & $\begin{array}{c}\text { CT } \\
\text { [y] }\end{array}$ & $\begin{array}{c}\text { IE } \\
\mathbf{( \% )}\end{array}$ & Assembly & $\begin{array}{c}\text { BU } \\
\text { [GWd/tU] }\end{array}$ & $\begin{array}{c}\text { CT } \\
\text { [y] }\end{array}$ & $\begin{array}{c}\text { IE } \\
\text { (\%) }\end{array}$ \\
\hline PWR1 & $9.6 \%$ & $20.2 \%$ & $6.2 \%$ & PWR16 & $1.1 \%$ & $-1.4 \%$ & $-3.4 \%$ \\
\hline PWR2 & $4.1 \%$ & $1.1 \%$ & $3.0 \%$ & PWR16 & $9.1 \%$ & $13.1 \%$ & $1.5 \%$ \\
\hline PWR3 & $-6.0 \%$ & $-0.3 \%$ & $0.8 \%$ & PWR16 & $4.4 \%$ & $12.9 \%$ & $-1.4 \%$ \\
\hline PWR4 & $1.5 \%$ & $-13.7 \%$ & $-2.3 \%$ & PWR16 & $-8.3 \%$ & $-9.9 \%$ & $-9.4 \%$ \\
\hline PWR5 & $2.3 \%$ & $2.9 \%$ & $-2.0 \%$ & PWR19 & $-8.6 \%$ & $2.2 \%$ & $-7.3 \%$ \\
\hline PWR7 & $-2.2 \%$ & $-20.8 \%$ & $-8.1 \%$ & PWR20 & $-2.9 \%$ & $1.4 \%$ & $-2.3 \%$ \\
\hline PWR8 & $2.4 \%$ & $-2.6 \%$ & $12.9 \%$ & PWR20 & $-2.8 \%$ & $3.3 \%$ & $-2.2 \%$ \\
\hline PWR9 & $-0.6 \%$ & $7.8 \%$ & $0.6 \%$ & PWR20 & $8.2 \%$ & $2.9 \%$ & $4.8 \%$ \\
\hline PWR10 & $-4.9 \%$ & $-0.1 \%$ & $-5.3 \%$ & PWR20 & $-0.6 \%$ & $-0.5 \%$ & $-0.8 \%$ \\
\hline PWR12 & $7.6 \%$ & $3.9 \%$ & $14.2 \%$ & PWR21 & $-7.0 \%$ & $-0.9 \%$ & $-5.0 \%$ \\
\hline PWR13 & $-4.4 \%$ & $5.6 \%$ & $5.7 \%$ & PWR21 & $-1.1 \%$ & $2.4 \%$ & $-1.1 \%$ \\
\hline PWR14 & $-12.4 \%$ & $-3.7 \%$ & $-9.3 \%$ & PWR25 & $-2.2 \%$ & $-0.2 \%$ & $1.2 \%$ \\
\hline PWR15 & $1.0 \%$ & $-0.6 \%$ & $24.2 \%$ & & & & \\
\hline
\end{tabular}


Table 3. Deviations (measured/declared -1) of the BU, CT, and IE of predicted compared to actual values of the 15 spectra with CT of $<20$ years

\begin{tabular}{|l|c|c|c|l|c|c|c|}
\hline Assembly & $\begin{array}{c}\text { BU } \\
\text { [GWd/tU] }\end{array}$ & $\begin{array}{c}\text { CT } \\
\text { [y] }\end{array}$ & $\begin{array}{c}\text { IE } \\
\mathbf{( \% )}\end{array}$ & Assembly & $\begin{array}{c}\text { BU } \\
\text { [GWd/tU] }\end{array}$ & $\begin{array}{c}\text { CT } \\
\text { [y] }\end{array}$ & $\begin{array}{c}\text { IE } \\
\text { (\%) }\end{array}$ \\
\hline PWR1 & $4.4 \%$ & $3.5 \%$ & $2.9 \%$ & PWR9 & $-1.6 \%$ & $6.5 \%$ & $0.0 \%$ \\
\hline PWR1 & $0.6 \%$ & $-0.5 \%$ & $0.4 \%$ & PWR10 & $-5.0 \%$ & $-0.3 \%$ & $-5.3 \%$ \\
\hline PWR2 & $4.9 \%$ & $4.8 \%$ & $3.5 \%$ & PWR14 & $-12.2 \%$ & $-3.3 \%$ & $-9.1 \%$ \\
\hline PWR2 & $14.2 \%$ & $12.5 \%$ & $9.4 \%$ & PWR16 & $1.4 \%$ & $-0.7 \%$ & $-3.2 \%$ \\
\hline PWR3 & $-6.3 \%$ & $-1.2 \%$ & $0.5 \%$ & PWR16 & $7.1 \%$ & $9.5 \%$ & $0.3 \%$ \\
\hline PWR4 & $4.9 \%$ & $2.2 \%$ & $-0.2 \%$ & PWR16 & $1.0 \%$ & $7.2 \%$ & $-3.5 \%$ \\
\hline PWR5 & $2.9 \%$ & $4.8 \%$ & $-1.7 \%$ & PWR16 & $-8.1 \%$ & $-9.5 \%$ & $-9.2 \%$ \\
\hline PWR7 & $3.5 \%$ & $-1.7 \%$ & $-4.6 \%$ & & & & \\
\hline
\end{tabular}


Table 4. Deviations (measured/declared -1) of the BU, CT, and IE of the spectra of predicted compared to actual values with $C T$ of $<8$ years

\begin{tabular}{|l|c|c|c|l|c|c|c|}
\hline Assembly & $\begin{array}{c}\text { BU } \\
\text { [GWd/tU] }\end{array}$ & $\begin{array}{c}\text { CT } \\
\text { [y] }\end{array}$ & $\begin{array}{c}\text { IE } \\
\mathbf{( \% )}\end{array}$ & Assembly & $\begin{array}{c}\text { BU } \\
\text { [GWd/tU] }\end{array}$ & $\begin{array}{c}\text { CT } \\
\text { [y] }\end{array}$ & $\begin{array}{c}\text { IE } \\
\text { (\%) }\end{array}$ \\
\hline PWR1 & $4.2 \%$ & $3.2 \%$ & $2.8 \%$ & PWR4 & $4.7 \%$ & $2.0 \%$ & $-0.3 \%$ \\
\hline PWR1 & $0.7 \%$ & $-0.4 \%$ & $0.5 \%$ & PWR5 & $2.8 \%$ & $4.7 \%$ & $-1.7 \%$ \\
\hline PWR2 & $5.1 \%$ & $5.3 \%$ & $3.6 \%$ & PWR7 & $3.5 \%$ & $-1.7 \%$ & $-4.6 \%$ \\
\hline PWR2 & $9.4 \%$ & $7.6 \%$ & $6.4 \%$ & PWR9 & $-1.6 \%$ & $6.4 \%$ & $0.0 \%$ \\
\hline
\end{tabular}


Table 5. Predicted BU, CT, and IE results of PWR9 along the length of the assembly when analyzed using the same cooling time for all measurements. From the 150-s mark to the 165-s mark, measurements were acquired near the edge of the fuel.

\begin{tabular}{|l|c|c|c|}
\hline & BU [GWd/tU] & CT [y] & IE (\%) \\
\hline Declared & $\mathbf{4 5 . 8}$ & 5.97 & 3.71 \\
\hline 30-s mark & 44.9 & 6.38 & 3.70 \\
\hline 70 -s mark & 45.3 & 6.38 & 3.72 \\
\hline 90 -s mark & 45.6 & 6.38 & 3.73 \\
\hline 120 -s mark & 46.0 & 6.38 & 3.76 \\
\hline $150-$ s mark & 44.7 & 6.38 & 3.69 \\
\hline 155 -s mark & 44.0 & 6.38 & 3.65 \\
\hline 160 -s mark & 39.1 & 6.38 & 3.38 \\
\hline $165-$ s mark & 28.4 & 6.38 & 2.75 \\
\hline
\end{tabular}


Table 6. Predicted BU, CT, and IE results of PWR16 from four corners and the average results.

\begin{tabular}{|l|c|c|c|}
\hline & BU [GWd/tU] & CT [y] & IE (\%) \\
\hline Declared & $\mathbf{4 0 . 4}$ & $\mathbf{1 7 . 1 5}$ & 3.60 \\
\hline $45^{\circ}$ & 41.0 & 17.02 & 3.48 \\
\hline $135^{\circ}$ & 43.3 & 18.79 & 3.61 \\
\hline $225^{\circ}$ & 40.8 & 18.38 & 3.48 \\
\hline $315^{\circ}$ & 37.1 & 15.52 & 3.27 \\
\hline Average & $\mathbf{4 0 . 6}$ & $\mathbf{1 7 . 4 3}$ & 3.46 \\
\hline Bias (average/declared-1) & $\mathbf{0 . 3 6 \%}$ & $\mathbf{1 . 6 3 \%}$ & $\mathbf{- 3 . 9 1 \%}$ \\
\hline
\end{tabular}


Table 7. Predicted BU, CT, and IE results of PWR20 from three corners and the average results.

\begin{tabular}{|l|c|c|c|}
\hline & BU [GWd/tU] & CT [y] & IE (\%) \\
\hline Declared & $\mathbf{3 4 . 0}$ & $\mathbf{2 7 . 1 9}$ & 3.10 \\
\hline $45^{\circ}$ & 33.1 & 27.57 & 3.03 \\
\hline $45^{\circ}$ overnight & 33.1 & 28.09 & 3.03 \\
\hline $225^{\circ}$ & 36.8 & 27.98 & 3.25 \\
\hline $315^{\circ}$ & 33.8 & 27.06 & 3.07 \\
\hline Average & $\mathbf{3 4 . 2}$ & $\mathbf{2 7 . 6 7}$ & 3.10 \\
\hline Bias(average/declared-1) & $\mathbf{0 . 4 7 \%}$ & $\mathbf{1 . 7 8 \%}$ & $\mathbf{- 0 . 1 4 \%}$ \\
\hline
\end{tabular}


Table 8. Deviations (measured/declared -1) of the BU, CT, and IE of predicted compared to actual values of the assemblies (note that not all assemblies were measured an equal number of times).

\begin{tabular}{|c|c|c|c|c|c|c|c|}
\hline Assembly & $\begin{array}{c}\text { BU } \\
\text { [GWd/tU] }\end{array}$ & $\begin{array}{c}\text { CT } \\
\text { [y] }\end{array}$ & $\begin{array}{c}\text { IE } \\
{[\%]}\end{array}$ & Assembly & $\begin{array}{c}\text { BU } \\
\text { [GWd/tU] }\end{array}$ & $\begin{array}{c}\text { CT } \\
\text { [y] }\end{array}$ & $\begin{array}{c}\text { IE } \\
{[\%]}\end{array}$ \\
\hline PWR1 & $0.0 \%$ & $-0.7 \%$ & $0.1 \%$ & PWR13 & $-5.2 \%$ & $-1.4 \%$ & $5.0 \%$ \\
\hline PWR2 & $2.7 \%$ & $2.8 \%$ & $2.1 \%$ & PWR14 & $-1.9 \%$ & $-3.1 \%$ & $-2.4 \%$ \\
\hline PWR3 & $-0.2 \%$ & $-1.4 \%$ & $4.8 \%$ & PWR15 & $-2.6 \%$ & $-7.1 \%$ & $21.3 \%$ \\
\hline PWR4 & $-11.0 \%$ & $-8.4 \%$ & $-10.3 \%$ & PWR16 & $0.9 \%$ & $-0.3 \%$ & $-3.5 \%$ \\
\hline PWR5 & $-14.9 \%$ & $-11.6 \%$ & $-13.1 \%$ & PWR19 & $-2.0 \%$ & $3.5 \%$ & $-3.0 \%$ \\
\hline PWR7 & $-7.3 \%$ & $-5.9 \%$ & $-11.2 \%$ & PWR20 & $0.8 \%$ & $-1.8 \%$ & $0.1 \%$ \\
\hline PWR8 & $-0.9 \%$ & $-2.4 \%$ & $10.5 \%$ & PWR21 & $-0.7 \%$ & $-1.0 \%$ & $-0.9 \%$ \\
\hline PWR9 & $0.2 \%$ & $1.4 \%$ & $1.2 \%$ & PWR22 & $0.2 \%$ & $0.6 \%$ & $4.2 \%$ \\
\hline PWR10 & $1.9 \%$ & $0.5 \%$ & $-1.0 \%$ & PWR25 & $-1.9 \%$ & $-0.2 \%$ & $1.3 \%$ \\
\hline PWR12 & $11.8 \%$ & $8.6 \%$ & $17.1 \%$ & & & & \\
\hline
\end{tabular}


Table 9. The average (Ave). measured ${ }^{60} \mathrm{Co} /{ }^{137} \mathrm{Cs}$ ratios of the assemblies.

\begin{tabular}{|c|c|c|c|c|}
\hline & \multicolumn{2}{|c|}{ August 2013 Measurements } & \multicolumn{2}{c|}{ October 2014 Measurements } \\
\hline Assembly & Ave. ${ }^{\mathbf{6 0}} \mathbf{C o} /{ }^{\mathbf{1 3 7}} \mathbf{C s}$ & Error (\%) & Ave. ${ }^{\mathbf{6}} \mathbf{C o} /{ }^{\mathbf{1 3 7}} \mathbf{C s}$ & Error (\%) \\
\hline PWR1 & $6.37 \mathrm{e}-6$ & 18.0 & $6.84 \mathrm{e}-6$ & 20.0 \\
\hline PWR2 & $1.88 \mathrm{e}-5$ & 8.7 & $1.61 \mathrm{e}-5$ & 6.8 \\
\hline PWR4 & $9.75 \mathrm{e}-6$ & 9.0 & $1.41 \mathrm{e}-5$ & 7.6 \\
\hline PWR5 & $8.11 \mathrm{e}-6$ & 12.5 & $1.50 \mathrm{e}-5$ & 7.0 \\
\hline
\end{tabular}


Table 10. Results of the methodology for the identification of assembly with anomalous reactor history in the reactor (see text for the meaning of \#sigma).

\begin{tabular}{|l|l|l|}
\hline \multicolumn{1}{|c|}{ Assembly } & \multicolumn{1}{|c|}{ \#sigma } & \multicolumn{1}{c|}{ Reactor Burn History } \\
\hline PWR11 & -23 & Burn 3 years, rest 2 years, burn 1 year \\
\hline PWR16 $\left(225^{\circ}\right)$ & 9 & Burn 2.5 years, rest 0.5 year, burn 1 year \\
\hline PWR17 & -11 & Burn 2 years, rest 2 years, burn 1 year \\
\hline PWR18 & -18 & $\begin{array}{l}\text { Burn 2 years, rest 1 year, burn 1 year, rest 1.5 years, burn } \\
\text { 0.5 year }\end{array}$ \\
\hline PWR22 & 9 & Burn 3 years \\
\hline PWR23 & 29 & Burn 1 year, rest 1 year, burn 1 year \\
\hline PWR24 & -9 & Burn 4 years, rest 10 years, burn 1 year \\
\hline
\end{tabular}

